\title{
ANÁLISE DE TENDÊNCIA DO MERCADO INTERNACIONAL DE AGLOMERADO'
}

Rommel Noce ${ }^{2}$, Juliana Mendes de Oliveira ${ }^{3}$, Rosa Maria Miranda Armond Carvalho², Márcio Lopes da Silva $^{4}$, José Luiz Pereira de Rezende ${ }^{5}$, Lourival Marin Mendes ${ }^{5}$ e Telma Regina da C.G. Barbosa ${ }^{6}$

RESUMO - Neste estudo, analisou-se, pelo método da regressão linear, a tendência do mercado internacional de aglomerado no período de 1990 a 2004. Observou-se tendência de crescimento tanto de produção quanto de exportação, com a ressalva de que o Brasil expande sua produção em ritmo mais acelerado que a produção mundial. Conclui-se que China, Ucrânia e EUA apresentaram maior crescimento, quanto à produção, exportação e importação, entre os mercados tradicionais, respectivamente, e que os mercados não-tradicionais mudaram tendências de crescimento superiores ao grupo dos principais importadores, especialmente o leste europeu.

Palavras-chave: Aglomerado, tendência de mercado e economia florestal.

\section{ANALYSIS OF INTERNATIONAL PARTICLEBOARD MARKET TENDENCY}

\begin{abstract}
This study analyzed international particleboard market tendency in the period from 1990 to 2004, using the linear regression method. Growth tendency was observed both for production and export, stressing that Brazil's production is expanding in a more accelerated rhythm than the world production. China, Ukraine and USA presented a greater production, export and import growth among the traditional markets, respectively, and the nontraditional markets presented greater growth tendencies, compared to the major import groups, especially East Europe
\end{abstract}

Keywords: Particleboard, market tendency and forest economy.

\section{INTRODUÇÃO}

O mercado internacional tornou-se um cenário estratégico para a indústria de base florestal brasileira cumprir sua missão empresarial, o que inclui contribuir para o desenvolvimento econômico-social da nação, em virtude da globalização econômica e da internacionalização dos negócios. A sobrevivência das organizações depende da expansão das operações, aquisição e fornecimento de insumos ou bens acabados de forma competitiva.
Há consenso em relação à representatividade que os produtos florestais assumem em nações de economia emergente, podendo contribuir efetivamente para a superação de dificuldades socioeconômicas, dada à diversidade e abundância de produtos que podem ser obtidos da floresta (NOCE et al., 2003).

No Brasil, a importância do setor florestal na economia é crescente, destacando-se o interesse renovado de diversas organizações pela atividade florestal (NOCE et al., 2005). A indústria de painéis particulados

\footnotetext{
${ }^{1}$ Recebido em 12.04.2006 e aceito para publicação em 20.02.2008.

${ }^{2}$ Programa de Pós-Graduação em Ciência Florestal da Universidade Federal de Viçosa (UFV). E-mail :<rommelnoce@ yahoo.com.br>. ${ }^{3}$ Programa de Pós-Graduação em Ciência e Tecnologia da Madeira da UFLA. E-mail : <julianameoli@ yahoo.com.br>.

${ }^{4}$ Departamento de Engenharia Florestal da UFV. E-mail : <marlosil@ufv.br>.

${ }^{5}$ Departamento de Ciências Florestais da Universidade Federal de Lavras. E-mail : <jlprezen@ufla.br>.

${ }^{5}$ Departamento de Administração da UFV. E-mail : <telma@ufv.br>.
} 
desempenha importante papel no cômputo geral do setor florestal. Movimenta recursos e gera empregos significativos, pela importância estratégica, já que, além de seus resultados específicos, supre a indústria de móveis, segmento no qual a nação começa a se destacar no mercado internacional.

A perspectiva de desenvolvimento e atuação em uma indústria depende da compreensão do contexto em que as empresas estão inseridas; essa percepção, entretanto, deve contemplar tendências futuras extrapolando a análise das condições atuais (WRIGHT et al., 2000).

É mais importante avaliar a velocidade de crescimento de variáveis econômicas do que considerar seus valores absolutos. Atributos como retrógrada, estagnada, desenvolvida ou inovadora podem ser associados às indústrias em virtude da comparação entre as velocidades de crescimento setorial diante de parâmetros globais do mercado (CONTADOR, 1995).

A análise de tendência temporal permite visualizar, no longo prazo, a direção do movimento da série temporal. A contribuição que representa para a visibilidade do mercado faz que as informações obtidas com sua operacionalização sejam constantemente demandadas para a definição de planos e políticas (GUJARATI, 2006).

Este estudoanalisou a tendência domercado internacional de aglomerado. Especificamente, buscou-se:

- Definir e comparar as taxas geométricas da produção das principais nações, incluindo a situação brasileira, produtoras de aglomerado, bem como as taxas geométricas de crescimento das importações dos mercados não-tradicionais.

\section{MATERIAL E MÉTODOS}

A regressão linear simples consiste em um método estatístico de ajuste a um conjunto de dados composto por uma variável dependente e uma independente. Especificamente para a análise de tendência, o tempo é definido como o regressor e o evento que se pretende analisar, como regressando (FINAMORE e GOMES, 1999).

Para verificar o comportamento da tendência em que se baseou a evolução do mercado internacional de aglomerado, foram calculadas as taxas geométricas de crescimento (TGC) para a produção, exportação e importação dos principais player's internacionais.
A taxa geométrica de crescimento é dada pela expressão:

$$
\mathrm{TGC}=(\text { antlogb-1) } \mathrm{x} 100
$$

em que:

TGC = taxa geométrica de crescimento; e

$\mathrm{b}=$ coeficiente de regressão.

Tais valores são estimados a partir do ajuste da equação de tendência, obtida através da série histórica da variável dependente, em metros cúbicos $\left(\mathrm{m}^{3}\right)$ :

$\log \mathrm{Y}=\mathrm{a}+\mathrm{bT}$

em que:

$$
\begin{aligned}
& \mathrm{Y}=\text { variável } \\
& \mathrm{a}=\text { constante da regressão; e } \\
& \mathrm{T}=\text { tendência. }
\end{aligned}
$$

A TGC expressa o crescimento da série, em termos porcentuais, por período de tempo analisado. Admitiuse que níveis de significância do parâmetro estimado "b", avaliado pelo teste " $\mathrm{t}$ ", superiores a 5\%, aumentam a probabilidade de erro em afirmar que a TGC é estatisticamente diferente de zero.

Utilizaram-se séries temporais de periodização anual com valores em metros cúbicos $\left(\mathrm{m}^{3}\right)$, no período de 1990 a 2004, obtidos no banco de dados da Food and Agriculture Organization of the United Nations (FAO, 2005).

O tratamento dos dados foi realizado com a utilização dos softwares E-Views 3.0 e Excel.

\section{RESULTADOS E DISCUSSÃO}

\subsection{Produção}

No ano de 2004, 89 países produziram aglomerado. As quatro principais nações produtoras de aglomerado são os EUA, o Canadá, a Alemanha e a China, com participações de 22,36; 12,43; 10,35; e $5,87 \%$ do cômputo da produção mundial, respectivamente. O Brasil apresenta-se como o $14^{\circ}$ produtor mundial, com participação de $1,86 \%$ da produção global (Quadro 1). 
Quadro 1 - Produção em 2004 e crescimento da produção dos principais produtores mundiais de aglomerado, 1990 a 2004 Table 1 - Production in 2004 and production growth of the major particleboard producers worldwide, 1990 to 2004

\begin{tabular}{|c|c|c|c|c|}
\hline & Nações & Volume $\left(\mathrm{m}^{3}\right)^{*}$ & $\%$ & TGC \\
\hline $1^{\circ}$ & EUA & 21.169 .360 & 22,36 & 9,35 \\
\hline $2^{\circ}$ & Canadá & 11.764 .000 & 12,43 & 11,97 \\
\hline $3^{\circ}$ & Alemanha & 9.800 .000 & 10,35 & 1,89 \\
\hline $4^{\circ}$ & China & 5.557 .000 & 5,87 & 14,55 \\
\hline $5^{\circ}$ & França & 4.250 .000 & 4,49 & 4,26 \\
\hline $6^{\circ}$ & Polônia & 4.080 .000 & 4,31 & 12,78 \\
\hline $7^{\circ}$ & Itália & 3.655 .000 & 3,86 & 2,55 \\
\hline $8^{\circ}$ & Rússia & 3.603 .000 & 3,81 & $-0,32 * *$ \\
\hline $9^{\circ}$ & Espanha & 3.100 .000 & 3,27 & 5,71 \\
\hline $10^{\circ}$ & Reino Unido & 2.653 .000 & 2,8 & 4,11 \\
\hline \multirow[t]{2}{*}{$14^{\circ}$} & Brasil & 1.762 .000 & 1,86 & 9,8 \\
\hline & Mundo & 94.672 .254 & 100 & 5,22 \\
\hline
\end{tabular}

*Valores referentes à produção no ano de 2004.

** Não se mostraram significativos a $5 \%$ de probabilidade.

Fonte: FAO, 2005 e dados da pesquisa.

A produção das 10 principais nações mostrou tendência crescente, à exceção da Rússia, que apresentou taxa negativa de crescimento geométrico (TGC) de $0,32 \%$, não significante a $5 \%$, resultado este que se justifica em parte pela dissolução da União Soviética. A produção mundial também se mostrou crescente, com TGC de 5,22\% (Quadro 1).

A China, a Polônia, o Canadá, o Brasil e os EUA apresentaram os crescimentos mais acelerados, com valores de 14,$55 ; 12,78 ; 11,97 ; 9,8$; e 9,35\%, para as respectivas TGCs (Quadro 1).

O crescimento apresentado pela China resulta da estratégia adotada para a estruturação de sua indústria. Aliada à política agressiva de importação de insumos, como madeira em tora, privilegia pequenas empresas que utilizam tecnologia nacional.

O Brasil apresenta a quarta maior TGC, superando os EUA (Estados Unidos) e aumentando a produção em ritmo superior àquele da produção mundial. Esse desempenho, relativamente positivo, é resultado de vantagens comparativas, como condições edafoclimáticas e base tecnológica em manejo florestal, que proporcionam rendimento silvicultural diferenciado, aliado aos avanços tecnológicos observados na indústria de particulados nacional. Isso apesar de o custo de insumos utilizados como adesivo prejudicar a competitividade do Brasil.

Nações como EUA, Alemanha, França, Itália, Espanha e Reino Unido apresentam TGC inferior ao do Brasil e volume de produção superior. Caso a tendência observada seja mantida, no longo prazo, o Brasil ultrapassará a participação de nações como Espanha e Reino Unido, tendo possibilidades de se posicionar entre os 10 maiores produtores mundiais de aglomerado. Diversos aspectos compõem a concretização dessa conquista da indústria brasileira de painéis particulados. A tendência de crescimento da produção de toras observada em estudo recente favorece esse cenário (NOCE et al., 2004). A expectativa de um déficit da oferta de madeira, no entanto, mostra-se como um obstáculo.

\subsection{Exportação}

Participaram como exportadores no mercado internacional de aglomerado 84 países no ano de 2004. Observam-se as participações mais expressivas do Canadá, Alemanha, Áustria e Bélgica com 34,88; 11,39; 6,44 ; e 6,39\%, respectivamente. O Brasil apresentase como o $47^{\circ}$ exportador mundial, com participação de $0,07 \%$ da exportação global (Quadro 2).

As exportações do Canadá, Alemanha, Áustria, França, Polônia, Ucrânia e República Tcheca mostraramse crescentes. Bélgica, EUA, Portugal e Brasil não apresentaram TGCs significantes a $5 \%$ de probabilidade, embora mostrassem valores positivos para as respectivas taxas. A exportação mundial de aglomerado mostrou-se crescente, com TGC de $8,88 \%$ (Quadro 2). Esse comportamento é coerente com o crescimento do volume do comércio internacional de produtos florestais, observado nas duas últimas décadas (NOCE et al., 2004a).

R. Árvore, Viçosa-MG, v.32, n.2, p.245-250, 2008 
Quadro 2 - Exportação em 2004 e crescimento da exportação dos principais produtores mundiais de aglomerado, 1990 a 2004

Table 2 - Exports in 2004 and export growth of the major particleboard producers, worldwide, 1990 to 2004

\begin{tabular}{rlccc}
\hline & Nações & Volume $\left(\mathrm{m}^{3}\right)^{*}$ & $\%$ & TGC \\
\hline $1^{\circ}$ & Canadá & 9.764 .000 & 34,88 & 15,51 \\
$2^{\circ}$ & Alemanha & 3.189 .000 & 11,39 & 8,61 \\
$3^{\text {o }}$ & Áustria & 1.804 .000 & 6,44 & 5,54 \\
$4^{\text {o }}$ & Bélgica & 1.789 .737 & 6,39 & $0,12^{* *}$ \\
$5^{\circ}$ & França & 1.610 .919 & 5,75 & 7,11 \\
$6^{\text {o }}$ & Polônia & 935.100 & 3,34 & 30,14 \\
$7^{\circ}$ & Ucrânia & 692.100 & 2,47 & 81,87 \\
$8^{\circ}$ & EUA & 568.664 & 2,03 & $0,64^{* *}$ \\
$9^{\text {o }}$ & República Tcheca & 557.000 & 1,99 & 24,89 \\
$10^{\circ}$ & Portugal & 538.000 & 1,92 & $1,01^{* *}$ \\
$47^{\circ}$ & Brasil & 20.200 & 0,07 & $1,63^{* *}$ \\
& Mundo & 27.993 .075 & 100 & 8,88 \\
\hline
\end{tabular}

*Valores referentes à exportação no ano de 2004

** Não se mostraram significativos a $5 \%$ de probabilidade.

Fonte: FAO, 2005 e dados da pesquisa.

Crescimentos mais acelerados das exportações foram observados na Ucrânia, Polônia e República Tcheca, com valores de 81,$87 ; 30,14 ; \mathrm{e} 24,89 \%$, respectivamente. Os valores relativamente altos observados nessas nações se justificam pela inserção no comércio internacional, a partir da dissolução da URSS (Ucrânia) e do fim do regime socialista do leste europeu (Polônia e República Tcheca) (Quadro 2).

O volume de exportação das ex-repúblicas soviéticas evoluiu, do início da década passada (1990) até meados da atual (2004), de $234.000 \mathrm{~m}^{3}$ para $1.489 .778 \mathrm{~m}^{3} \mathrm{de}$ aglomerado. A exportação total dessas nações, no entanto, apresenta-se inferior à quantidade observada no início da referida década, de 5.607 .700 e $6.397 .000 \mathrm{~m}^{3}$, respectivamente (FAO, 2005).

O Canadá destaca-se como maior exportador mundial e apresenta uma TGC de $15,51 \%$ superior à média mundial. A persistir a tendência observada, a hegemonia canadense deve ser mantida. As condições geopolíticas privilegiadas em relação ao mercado norte-americano, o principal importador de aglomerado, contribuem para tanto.

O Brasil não apresentou TGC das exportações de aglomerado significativa a $5 \%$ de probabilidade, sendo de 1,63\%. A pouca expressividade da evolução das exportações brasileiras justifica-se pela absorção de grande parte da produção de aglomerado pela indústria moveleira. Esta se mostrou competitiva no mercado internacional, o que indica que foi agregado valor ao produto, conforme Coelho e Berger (2004).

\subsection{Importação}

Notou-se que cerca de 186 nações importaram aglomerado em 2004, destacando-se como principais importadores EUA, Alemanha, Reino Unido e China, correspondendo a 36,$53 ; 5,32 ; 4,48$; e $3,53 \%$, respectivamente (Quadro 3).

Considerando os 10 principais importadores no ano de 2004, apenas Reino Unido, França e Países Baixos não apresentaram TGC crescentes e significativos a $5 \%$ de probabilidade, e os dois últimos apresentaram TGCs com valores negativos. A importação desse grupo de 10 países exibiu TGC de $7,08 \%$ no total, indicando tendência crescente dos principais importadores, quando se considera a quantidade agregada. Destaca-se o crescimento das importações dos EUA e China com TGCs de 15,58 e $15,28 \%$, respectivamente. Os EUA representam mais de um terço do mercado, totalizando, juntamente com a China, 40,06\% da demanda internacional do ano de 2004. As crescentes importações se destinam a abastecer as indústrias moveleiras desses países, em que a norte-americana prioriza o potencial de seu mercado interno, enquanto a chinesa se tem desenvolvido e avançado sobre diversos segmentos do mercado internacional (Quadro 3).

Os mercados da Dinamarca e da Espanha se mostraram com TGCs pouco acima da média dos principais importadores $(8,17$ e $7,27 \%$, respectivamente). 


\subsection{Mercados não-tradicionais}

Identificou-se um grupo de 25 países, que apresentaram TGCs relativamente altas, além dos mercados tradicionais. Essas nações, em conjunto, representam $20,91 \%$ das importações observadas em 2004. O crescimento de suas importações em conjunto é semelhante ao dos EUA, sendo de $15,57 \%$ e muito acima da média mundial de 8,88\% (Quadro 4).

Quadro 3 - Importação em 2004 e crescimento da importação dos principais mercados de aglomerado, 1990 a 2004 Table 3 - Imports in 2004 and import growth of the major particleboard markets, 1990 to 2004

\begin{tabular}{clccc}
\hline & Nação & Volume $\left(\mathrm{m}^{3}\right)^{*}$ & $\%$ & TGC \\
\hline $1^{\circ}$ & EUA & 10.225 .499 & 36,53 & 15,58 \\
$2^{\circ}$ & Alemanha & 1.488 .000 & 5,32 & 1,78 \\
$3^{\circ}$ & Reino Unido & 1.254 .895 & 4,48 & $0,44^{* *}$ \\
$4^{\circ}$ & China & 988.522 & 3,53 & 15,28 \\
$5^{\text {o }}$ & Dinamarca & 842.797 & 3,01 & 8,17 \\
$6^{\circ}$ & Espanha & 758.000 & 2,71 & 7,27 \\
$7^{\circ}$ & Coréia & 681.000 & 2,43 & 3,18 \\
$8^{\circ}$ & França & 664.058 & 2,37 & $-0,81^{* *}$ \\
$9^{\circ}$ & Itália & 663.266 & 2,37 & 4,94 \\
$10^{\circ}$ & Países Baixos & 627.900 & 2,24 & $-0,31^{* *}$ \\
Subtotal & & 18.193 .937 & 64,99 & 7,08 \\
& Mundo & 27.993 .075 & 100 & 8,88 \\
\hline
\end{tabular}

*Valores referentes à importação no ano de 2004. ** Não se mostraram significativos a 5\% de probabilidade. Fonte: FAO, 2005 e dados da pesquisa.

Quadro 4 - Importação em 2004 e crescimento da importação dos mercados não-tradicionais de aglomerado, 19902004 Table 4-Imports in 2004 and import growth of the nontraditional particleboard markets, 19902004

\begin{tabular}{|c|c|c|c|c|}
\hline & Nação & Volume $\left(\mathrm{m}^{3}\right)^{*}$ & $\%$ & TGC \\
\hline $1^{\circ}$ & Polônia & 604.800 & 2,16 & 30,48 \\
\hline $2^{\circ}$ & Rússia & 552.000 & 1,97 & 51,60 \\
\hline $3^{\circ}$ & Suécia & 523.000 & 1,87 & 8,25 \\
\hline $4^{\circ}$ & Canadá & 389.055 & 1,39 & 9,96 \\
\hline $5^{\circ}$ & Romênia & 362.000 & 1,29 & 55,73 \\
\hline $6^{\circ}$ & Áustria & 317.000 & 1,13 & 7,61 \\
\hline $7^{\circ}$ & Bélgica & 281.033 & 1,00 & 3,54 \\
\hline $8^{\circ}$ & Suíça & 279.934 & 1,00 & 3,68 \\
\hline $9^{\circ}$ & Ucrânia & 278.790 & 1,00 & 68,58 \\
\hline $10^{\circ}$ & República Tcheca & 242.000 & 0,86 & 18,25 \\
\hline $11^{\circ}$ & Hungria & 229.000 & 0,82 & 26,25 \\
\hline $12^{\circ}$ & Servia Montenegro & 227.000 & 0,81 & 50,95 \\
\hline $13^{\circ}$ & Lituânia & 226.000 & 0,81 & 53,78 \\
\hline $14^{\circ}$ & Eslováquia & 225.000 & 0,80 & 34,32 \\
\hline $15^{\circ}$ & Bielorrúsia & 177.100 & 0,63 & 94,32 \\
\hline $16^{\circ}$ & Cazaquistão & 150.800 & 0,54 & 116,10 \\
\hline $17^{\circ}$ & Eslovênia & 149.827 & 0,54 & 16,00 \\
\hline $18^{\circ}$ & Croácia & 147.000 & 0,53 & 23,03 \\
\hline $19^{\circ}$ & Azerbaijão & 97.568 & 0,35 & 51,22 \\
\hline $20^{\circ}$ & Bulgária & 96.000 & 0,34 & 41,65 \\
\hline $21^{\circ}$ & Noruega & 86.846 & 0,31 & 4,10 \\
\hline $22^{\circ}$ & Portugal & 73.000 & 0,26 & 3,57 \\
\hline $23^{\circ}$ & Peru & 57.000 & 0,20 & 21,76 \\
\hline $24^{\circ}$ & Cyprus & 53.602 & 0,19 & 8,18 \\
\hline \multirow[t]{3}{*}{$25^{\circ}$} & Bósnia Ezergovina & 27.200 & 0,10 & 31,25 \\
\hline & Subtotal & 5.852 .555 & 20,91 & 15,57 \\
\hline & Mundo & 27.993 .075 & 100 & \\
\hline
\end{tabular}

*Valores referentes à importação no ano de 2004. Fonte: FAO, 2005 e dados da pesquisa. 
Como nas exportações, as maiores TGCs de importação são verificadas nos países do Leste Europeu. Destacam-se as ex-repúblicas soviéticas do Cazaquistão, Bielorrússia, Ucrânia, Lituânia, Rússia e Azerbaijão, que apresentaram TGCs de 116,10; 94,32; 68,58; 53,78; 51,60 ; e 51,22\%, respectivamente. Outras nações com histórico de movimentos separatistas, como Sérvia Montenegro, Eslováquia e Bósnia Ezergovina com TGCs de 50,95; 34,32; e 31,25\%, respectivamente, além da Polônia, Romênia e Bulgária, que apresentaram TGCs de 30,$48 ; 55,73$; e $41,65 \%$, respectivamente.

A TGC das importações do mercado alternativo, considerado como essas 25 nações, é mais que o dobro da taxa de crescimento do mercado principal, composto pelos 10 principais importadores.

\section{CONCLUSÃO}

Nas condições em que foi desenvolvido este estudo, conclui-se que:

- O mercado internacional de aglomerado apresenta tendência de expansão, considerando-se valores históricos de produção e exportação.

- O Brasil expande sua produção em ritmo mais acelerado que a produção mundial, mas não apresenta tendência significativa de aumento das exportações.

- Nos mercados tradicionais, a China, Ucrânia e EUA destacam-se com as maiores taxas de crescimento da produção, exportação e importação, respectivamente.

- Mercados não-tradicionais apresentam TGCs superiores ao grupo dos principais importadores, especialmente no Leste Europeu.

\section{REFERÊNCIAS}

COELHO, M. R. F.; BERGER, R. Competitividade das exportações brasileiras de móveis no mercado internacional: uma análise segundo a visão desempenho. Revista FAE, v.7, n.1, p.51-65, 2004.

CONTADOR, J. C. Planejamento estratégico: recomendações sobre os ambientes externos e internos. Revista de Administração de Empresas - RAE, v.35, n.2, p.43-56, 1995.

R. Árvore, Viçosa-MG, v.32, n.2, p.245-250, 2008
FINAMORE, E. B. M. C.; GOMES, A. P. Uma alternativa a análise de tendências em séries temporais. In: CONGRESSO BRASILEIRO DE ECONOMIA E SOCIOLOGIA RURAL, 37, 1999 , Foz do Iguaçu. Anais... Brasília: SOBER, 1999. CD-ROM.

FOOD AND AGRICULTURE ORGANIZATION OF THE UNITED NATIONS - FAO. Forestry data bilateral trade matrices. Disponivel em:<http://faostat.fao.org/faostat/

form? collection=Forestry.Primary $\&$ Domain=Forestry \&servlet $=1 \&$ hasbulk $=0 \&$ version $=$ ext $\&$ language $=E N>$ Acesso em: 15 de fev. de 2005.

GUJARATI, D. N. Econometria básica. Rio de Janeiro: Elsevier, 2006. 812p.

NOCE, R.; CARVALHO, R. M. M. A.; SOARES, T. S. Análise de tendência da produção brasileira de toras de madeira. In: VII CONGRESSO E EXPOSIÇÃO INTERNACIONAL SOBRE FLORESTAS, 7., 2004, Brasília. Anais... Rio de Janeiro: Instituto Ambiental Biosfera, 2004. v.1, p.17-18.

NOCE, R. et al. O desempenho do Brasil nas exportações de madeira serrada. Revista Árvore, v.27, n.5, p.695-700, 2003.

NOCE, R. et al. Análise de risco e retorno do setor florestal: produtos da madeira. Revista Árvore, v.29, n.1, p.77-84, 2005.

NOCE, R.; SOARES, T.S.; CARVALHO, R. M. M. A. Tendência do volume de comércio mundial de produtos madeireiros no período de 1980 a 2000. In: CONGRESSO BRASILEIRO DE DESENVOLVIMENTO SUSTENTÁVEL PARAA INDÚSTRIA DE BASE FLORESTAL E DE GERAÇÃO DE ENERGIA, 2., 2004, Belo Horizonte. Revista Madeira 2004. Belo Horizonte: AMS, 2004a. v.2. p.44-45.

WRIGHT, P.; KROLL, M. J.; PARNELL, J. Administração estratégica. São Paulo: Atlas, 2000. 433p. 